\title{
A mixed methods exploratory study of the utility of social cognitive career theory for research into the careers of entrepreneurial Emirati women in Dubai
}

\begin{tabular}{|c|c|}
\hline \multicolumn{2}{|c|}{$\begin{array}{l}\text { Authors: } \\
\text { Pamela Hawkswell } \\
\text { Peter Mcllveen }{ }^{1} \\
\text { Patricia N. Hoare }\end{array}$} \\
\hline \multicolumn{2}{|c|}{$\begin{array}{l}\text { Affiliations: } \\
{ }^{1} \text { School of Education, } \\
\text { University of Southern } \\
\text { Queensland, Toowoomba, } \\
\text { Australia }\end{array}$} \\
\hline \multicolumn{2}{|c|}{$\begin{array}{l}{ }^{2} \text { School of Psychology and } \\
\text { Counselling, University of } \\
\text { Southern Queensland, } \\
\text { Toowoomba, Australia }\end{array}$} \\
\hline \multicolumn{2}{|c|}{$\begin{array}{l}\text { Corresponding author: } \\
\text { Peter Mcllveen, } \\
\text { peter.mcilveen@usq.edu.au }\end{array}$} \\
\hline \multicolumn{2}{|c|}{$\begin{array}{l}\text { Dates: } \\
\text { Received: } 13 \text { Oct. } 2021 \\
\text { Accepted: } 28 \text { Oct. } 2021 \\
\text { Published: } 15 \text { Dec. } 2021\end{array}$} \\
\hline \multicolumn{2}{|c|}{$\begin{array}{l}\text { How to cite this article: } \\
\text { Hawkswell, P., Mcllveen, P., \& } \\
\text { Hoare, P.N. (2021). A mixed } \\
\text { methods exploratory study of } \\
\text { the utility of social cognitive } \\
\text { career theory for research } \\
\text { into the careers of } \\
\text { entrepreneurial Emirati } \\
\text { women in Dubai. African } \\
\text { Journal of Career } \\
\text { Development, 3(1), a46. } \\
\text { https://doi.org/10.4102/ajcd. } \\
\text { v3i1.46 }\end{array}$} \\
\hline \multicolumn{2}{|c|}{$\begin{array}{l}\text { Copyright: } \\
\text { (C) 2021. The Authors. } \\
\text { Licensee: AOSIS. This work } \\
\text { is licensed under the } \\
\text { Creative Commons } \\
\text { Attribution License. }\end{array}$} \\
\hline \multicolumn{2}{|l|}{ Read online: } \\
\hline 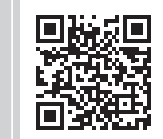 & $\begin{array}{l}\text { Scan this QR } \\
\text { code with your } \\
\text { smart phone or } \\
\text { mobile device } \\
\text { to read online. }\end{array}$ \\
\hline
\end{tabular}

Background: Social cognitive career theory (SCCT) is one of the leading theories within the literature of career development, but there is marginal evidence of its applicability within the diverse nations and cultures of the Middle East and Arab nations.

Objectives: The research involved a mixed methods exploratory design with an aim to determine SCCT's utility in the context of Dubai and with a specific focus on the careers of Emirati women.

Method: Study 1 used interviews to explore contextual factors affecting women's careers. Study 2 used a survey to measure core SCCT constructs, namely self-efficacy and outcome expectations, and their relations with work engagement.

Results: The qualitative data from the interviews and quantitative data from the survey found salience in factors that were consistent with the tenets of SCCT.

Conclusion: The findings provide evidence of SCCT's potential utility in this cultural context; however, future research should extend into a broader and larger sample of workers in Dubai and the UAE.

Keywords: social cognitive career theory; self-efficacy; outcome expectations; work engagement; Dubai; women's careers.

Dubai is one of the world's high profile economic and cultural hubs. However, research into the careers of people of the United Arab Emirates (UAE) and citizens of Dubai, women in particular, is uncommon in specialist international career development journals. Accordingly, the present research had two aims. Firstly, given the global significance of Dubai as a commercial hub, we sought to address this research gap in the career development literature by exploring career development of women in the private sector in Dubai. Secondly, we sought to explore the utility of a Western theory, namely the social cognitive career theory (Brown \& Lent, 2019; Lent \& Brown, 2019) in this specific context and demographic group.

\section{Women's entrepreneurial careers in Dubai}

In recent decades there has been emerging government programmes to enhance Emirati women's careers, including the National Strategy for the Empowerment of Emirati Women (United Arab Emirates Government, 2021), the Dubai Women Establishment (Government of Dubai, 2021) and, the Dubai Business Women Council (Dubai Chamber of Commerce and Industry, 2021). The Dubai Women's Establishment, for example, aims to nurture the next generation of Emirati women leaders who will serve as role models to young women in the wider society, with the establishment playing an active role to equip these women to fulfil this task. Despite these initiatives, there is limited research pertaining to women's careers in Dubai.

The disciplinary field of business studies acknowledges a history of significant social, cultural, and legal constraints on women's careers in the UAE (e.g. Erogul, 2011; Erogul, Rod, \& Barragan, 2019; Gallant, Majumdar, \& Varadarajan, 2010; Marmenout \& Lirio, 2014). With respect to the issues of gender, men may be both an inhibitor and promoter of women's entrepreneurship, with inhibition diminished by the support of close male networks, particularly family (Barragan, Erogul, \& Essers, 2015; Erogul, 2011). Calls for a feminist perspective on women in business aim to address a discourse that limits women to the traditional role of mother (Barragan et al., 2015; Erogul et al., 2019) which reflects societal norms for women such as marriage, family, and modesty (Marmenout \& Lirio, 2014). Furthermore, young Emirati women may be inclined towards an entrepreneurial career if 
there is educational preparation for business (Gallant et al., 2010). Whilst the present study is within the private sector, we acknowledge similar constraints on women's careers in the public sector (cf. Williams, Wallis, \& Williams, 2013).

\section{Social cognitive career theory in the United Arab Emirates context}

The social cognitive career theory (SCCT) has diverse theoretical, empirical, and practical utility (Brown \& Lent, 2019; Lent \& Brown, 2019); however, its utility for non-Western cultures requires further research (Sheu \& Bordon, 2017). The limited research using SCCT in the Arabian region includes a study involving interviews with UAE women to explore the factors that have an influence on their careers in the IT sector which found family to be a major influence (Howe-Walsh, Turnbull, Khan, \& Pereira, 2020). Another qualitative study using interviews explored young Emiratis' bias against work in the private sector and their notions of agency, but it did not specifically report findings related to self-efficacy in terms of the SCCT (Al-Waqfi Mohammed \& Forstenlechner, 2012). A quantitative SCCT-informed research into Emirati school children's interests in a STEM career used Program for International Student Assessment (PISA) data for the UAE but did not find a predictive relation between self-efficacy and aspirations for a STEM career (Cairns \& Dickson, 2020). Another quantitative survey research by Badri, Mohaidat, Ferrandino and El Mourad (2013) used SCCT work satisfaction model (Lent \& Brown, 2006) to inform research into teachers in Abu Dhabi, a neighbouring Emirate of Dubai. Contrary to SCCT hypotheses, Badri et al. found no direct predictive relation between self-efficacy, which is core to the SCCT, and job satisfaction. Goal support was also found to be indirectly related to work satisfaction via work conditions and selfefficacy as reflected in goal progress. Albeit limited, these qualitative and quantitative research studies are suggestive of SCCT's potential utility for research into Emirati women's careers, but more research is needed to affirm its status as a useful theory for this region.

\section{The present research}

The present research was exploratory by design (i.e. to explore the potential of the SCCT in a novel cultural context); therefore, we used a mixed methods sequential exploratory design (Hanson, Creswell, Clark, Petska, \& Creswell, 2005). Firstly, a qualitative study sought to explore the contextual factors that may influence women's career satisfaction. Secondly, a quantitative study focused on the core social cognitive variables, namely self-efficacy and outcome expectations, and their relation with women's sense of engagement in their careers.

\section{Study 1 \\ Participants}

Five women participated in the interviews about their careers. They were residents of Dubai, employed, and studying at a women's college, nearing completion of a 4-year bachelor's degree programme. Their ages ranged from 23 to 33 years. Two participants were married having children. All were employed in non-managerial positions at the time of the interview and were from a wide range of career backgrounds - banking, insurance and finance and accounting - with three out of five working or having worked in banks, which was consistent with females predominantly opting to work in the banking sector in the UAE.

Pseudonyms are used hereafter. Salma (27 years of age) lived with her family of origin and had worked in the insurance sector for 8 years before switching to a governmental position in 2014. Salma majored in Human Resources during her college years. Sumaya (28 years of age) was married, had a young daughter, and worked for the banking industry for 8 years before switching to the government sector 2 years prior to the interview. Sumaya majored in Human Resources. Dana (23 years of age) was working in a private bank. Dana had studied nanoengineering on a Government-sponsored scholarship in Canada for 3 years before returning home. She then pursued a business degree to better accommodate her knowledge and skills for the banking industry. Fatma (33 years of age) was married with one child and expecting a second. She had spent 8.5 years in the private sector at two banks and an airline and had worked for the government during the 4 years prior to the interview. Her intention was to re-join the private sector within a year. Amina (30 years of age) worked in the government sector after working for 8 years in a private bank.

The participants were personally invited by the interviewer to participate in the study and were provided with written information about what was required of their participation. The invitations were given in English (the language of instruction at the college) and reflected respect for the culture and demarcation of boundaries for the participants and the researchers. The participants agreed to audio record their responses during the interview. They were assured of maintaining anonymity of their identity and therefore pseudonyms were used throughout the transcripts and in the resulting reporting of the findings.

The interviewer was a teacher at the participants' college. She is an Australian citizen of White European background. She has extensive expatriate professional experience in the UAE, including teaching female Emirati students for more than 18 years. The participants knew the interviewer in her role as a teacher. This knowledge of the interviewer as a member of college with significant cultural understanding of the UAE and its Islamic traditions legitimised her role and assured the participants that she has much respect for local customs. The interviewer identified as both an insider and an outsider: an insider as a woman exploring women's careers and an outsider as person of different cultural heritage. To manage this complex balance of insider-outsider, the interviewer participated in regular supervision meetings with the project supervisor.

These meetings included reflective discussions to ensure that the interviewer was aware of the potential cultural concerns and influences on her interpretation of the interview data. The research was approved by the ethical review board of the University of Southern Queensland (Approval: H15REA252). 


\section{Procedure}

The design of the interview questions was informed by the theoretical tenets of the SCCT with the aim of exploring how the participants experienced and expressed (cognitively, behaviourally, emotionally) contextual factors (e.g. family), self-efficacy, outcome expectations, and goals with regard to their careers. For example, questions pertaining to contextual matters included the following:

$[H]$ ow might your family and friends feel if you go on to be highly successful in your career? How might your friends feel if you go on to be highly successful in your career? How might society feel if you go on to be highly successful in your career?

The interview questions were sent to the participants in advance. The questions (provide the questions) that may have resulted in answers reflecting cultural influence were carefully worded to avoid signs of bias or judgement. The interviews lasted between 30 and $60 \mathrm{~min}$ and occurred over a period of 3 weeks. Immediately after the interview, notes were taken in an effort to supplement the transcripts. Transcriptions were completed within 2 days of an interview and then returned to the participants for their checking to comment on any misunderstandings or misrepresented responses, and to add any other relevant points that would enhance the interpretation of data.

\section{Data analysis}

The transcripts were analysed using Thematic Analysis (Braun \& Clarke, 2006, 2013). A manual approach with a coloured coding table matching the constructs of the SCCT was used. The entire transcripts were copied and colourcoded to the 'original data' column with thoughts on the content added to the second 'comments' column. Additional comments were added using the comments tool on the review option in Microsoft word. These comments represented initial justification for the colour-coding and ultimately linked extracts to the constructs of the SCCT. A second table headed 'Themes from Codes for aspects of the $\mathrm{SCCT}^{\prime}$, was drawn up and then data from the five interview transcripts were organised according to the SCCT constructs. Those data that were considered relevant to career paths but that did not fit specifically into the SCCT constructs were listed under an additional heading 'other'. Data were collated to facilitate identification of patterns across the dataset, instead of being constrained by the questions, which is a technique recommended by Braun and Clark (2013).

\section{Findings}

In alignment with SCCT work satisfaction model (Lent \& Brown, 2006), the Findings section is organised with respect to themes that represent contextual supports, resources, and obstacles, and work conditions, both proximal (e.g. family-oforigin, own family) and distal (e.g. workplace, societal expectations). Matters pertaining to gender - of being a woman in this specific context - imbue the findings. Accordingly, the issues pertaining to gender are integrated into the themes.

\section{Family-of-origin}

Maternal figures have been a significant proximal influence on the careers of the participants. Salma recounted an almost 180-degree turnaround in the attitude displayed by her mother from when she first joined the private sector to the present time. She excused her mother's initial reaction to her working in the private sector by saying that, 'old people have the belief that Government jobs are more secured, have less hours and less stress' but then conceded that her mother was, 'eventually understanding and supporting ... "til today"' of her decision to pursue a career in insurance in the private sector. Of particular importance to Salma was the way in which her mother motivated and encouraged her by telling her, 'You can do better than this, these are not your limits... you're capable of better than this', as she was the only one in the family undertaking further study. Dana also credited her mother as, 'actually giving me the idea of pursuing this path (business) rather than the engineering, although they [sic] were very supportive of that', after she forewent a scholarship at an overseas university and returned home to live and work. Her mother was again identified as being the major motivator behind the idea that she would eventually start a family business when she felt she had the required experience.

All participants spoke of the obvious and somewhat expected pride and happiness expressed by their families regarding their career achievements to date, as reflected in Fatma's comment, 'they will always be proud of me of course... because they know I worked hard on myself to reach that position or that stage'. The influence of encouragement from their family members was also noted, as exhibited by Sumaya, in the form of them, 'wanting me to be better and getting a higher position and higher certificate', and by Dana, in her observation of, 'they feel that being successful in your career is a very good thing ... something to be proud of ... and they would like to see their kids being very successful'. Amina's family can be seen to contravene traditional societal norms to a certain extent by encouraging her to take up study abroad. The unusual nature of this encouragement is demonstrated by Amina's rhetorical remark, 'I got a scholarship to do the master's internationally. Will they allow me to go ... yes ... !'. These words of Amina give an indication of the societal tradition in which females are generally not encouraged to move abroad if it means separation from family members. In addition, the fact that Amina was single, reinforced the significance of the family's decision that has spurred her on to consider undertaking doctoral studies abroad in the future. This was closely linked to her obligation to reach the top of her field in academia.

\section{Own-family}

Work-life balance was mentioned by the participants as an important obligation especially where their family was concerned. It appears to be mandatory for females pursuing a career, to fulfil the role of being available for other family members. This was illustrated in Salma's comment in relation to undertaking further study, 'And of course it is my 
duty to keep the balance between my work and my family', and in Amina's previous comment, '... if I do the study abroad the challenge will be double as I'm quite tied to the family'. As such, it is difficult to find out whether the obligation was self-imposed or was imposed by family or society, both of which are the wider communities to which the participants belong. Regardless of these two possibilities, a sense of obligation to the family was evident amongst these participants.

In contrast, Dana saw further commitment to study as possibly causing her to have to, 'give up so much of her social life and leisure life in general' but admitted that if she wanted to focus on her career, '... my lifestyle would be dedicated to studying and working hard'. The fact that Dana lived abroad for study for 2 years sharing a flat with Western students has undoubtedly granted her this somewhat alternative perspective in relation to the obligation and pursuit of career goals, although not necessarily at the neglect of family.

As was to be expected, other obligations fell more directly under career goals. For instance, Sumaya was determined that the next position she looked for, ' $\ldots$ has to be related to HR because I studied so I want to apply what I studied in my work', and was in direct contrast to her taking up previous positions which she referred to as 'just getting something'. The reason behind Dana's decision to quit her engineering course abroad, return home, and switch to the business field, was revealed in her words, 'I knew if I did engineering I just wouldn't be happy ... I was just more interested in the business subjects'. The fact that she had found parts of the engineering course tough led her to this conclusion. She appeared to have gone from strength to strength, with an awareness of what is expected for success in the private sector in her comment:

$[\ldots I]$ 'm still pursuing further education ... it's a very important part for you to succeed ... if you have a lower level education they won't much consider you ... even though you're good at the job.

Her expectations in relation to success in her future career path hinged on her getting more experience to perhaps open a family business, becoming more financially independent to explore other avenues, and growing as a person.

Amina also saw her own success as being intertwined with the success of her future family and, ultimately, the society in her observation, 'If I add anything to myself, definitely it will be adding value to them and the UAE as we are like a small community'. She made reference to moving up a job hierarchy in the form of a 'good position, in a good field in a good organisation' to exemplify this observation. She was, however, well aware of the fact as to how society sees a single female pursuing a doctorate when she stated, 'I'm not married and I know the society will not agree with me taking another degree, especially a PhD and being highly educated'. She defended her status with a lengthy explanation amounting to being kept busy by running around with 'unnecessary stuff' or by filling the hours with study. She explicitly distinguished between what she perceived as the somewhat-harsh choices given by society as keeping busy with study or having children and challenges the ultimatum, by saying if she does not find 'a person really good to marry', she will continue her career and earn a PhD.

\section{Workplace}

Employers' influence plays a pivotal role in the participants' perspectives of career advancement, an influence that is both positive and negative in nature. Salma made special mention of what she perceived to be gender discrimination, generalising that: '.. there are still people in the world who as CEOs will not be happy to give promotions to women and who would prefer men instead of women and girls'. She consolidated her belief by adding that, '... even if you are working double the men, still they are not happy with you, just because you're a woman'. Others spoke of managers as not being supportive, with Dana, in particular, wondering if 'they really want you to become a better person...or grow in the company...or they just want you to stay there because you're good at your job and that benefits them alone'. Fatma, whilst seeing the initial project set by the manager as being a direct challenge to her as a new staff member, acknowledged that when she succeeded, he was impressed, and gave her positive feedback.

Salma vented her frustration when she told about her experience of not receiving a promotion after 2 years when she emphatically stated, 'But of course we can do work, we are better than men!' Her indignation of and eventual triumph over the situation was summed up in her final reaction, that of feeling:

$[A]$ ngry and making me go and search for another higher position just to show my manager I deserved more than this because when I was there he didn't understand my true value but after I left what happened ... he hired three employees!

Perhaps unknowingly, she was exhibiting self-efficacy here along with a degree of outcome expectation - that of being confident that she would get a better position if she made the effort to look elsewhere.

Positive experiences in relation to managerial support, as reported by Fatma, ranged from a manager who was partially supportive because, 'he was too busy with what he was doing ... and when we had that one-to-one meeting, he was just trying to wrap up fast' to an HR lady working with the manager who, 'was always supportive'. She then went on to recollect that the best experience came from a different bank describing the years here as, 'the most important period of my career because of the amount of support I got from my managers and my colleagues', support that came in the form of various trainings to enhance learning and skills. Her outcome expectations from completing these trainings then were to be better equipped to carry out dayto-day tasks and responsibilities and ultimately work towards promotion. 


\section{Societal expectations}

Dana was mindful of the fact that today's society wanted and expected women to be more successful in the workplace. This encouragement has been given by governmental actions and by other female groups throughout the UAE. She opined that 'it would be a very good thing' in relation to her succeeding in a role previously only considered for men, and the subsequent effect this success would have on women in society. Now that there are more female than male students enrolled in higher education. It stands to reason that, as these females graduate, they will occupy a larger percentage of the local workforce and may want to exert more control over their career progress. Fatma was more direct and went one step further in her perception of societal expectations, linking the concept of being a role model to friends or their friends in terms of 'giving back to your country'. She equated society with the broader aspect of the country, which is reflected in her statement, 'Whatever you are doing you are giving back to society, giving back to your country, and this is what is expected from you'.

The participants acknowledged that they were women working in a society that predominantly favours males, but they were quick to argue that this bias may not necessarily be the case for them. This was reflected in Salma's comment:

$[\ldots N]$ owadays our society is more open ... and women are half of the society so we are being supported by our government, family, friends, so when we are highly successful in our career, it will be a positive feeling from them.

Uppermost in this participant's mind was the late ruler his Highness Shaikh Mohamad bin Zayed (1918-2004), who did much to encourage sexual equality, including encouraging women to serve in the police and armed forces.

Dana's comments concurred with Salma's perspective by saying about society, '... they will actually be very supportive because they do want to see people in the UAE go on to be highly successful, especially women ...'. She backed this up by adding, 'In this recent year, there are actually a lot of women pursuing different kinds of jobs and positions that weren't there for them, only for men', and then alludes as to how it would be 'a very good thing' if society saw them 'getting there'. The importance of giving back to society through being a role model, either to friends or to people in general, was emphasised by Fatma who saw it as a societal expectation.

In contrast, Sumaya raised a somewhat negative issue of some people in society being presumably unsupportive, when she said, 'Ah society ... I will face some jealousies in my life for how she reached this position ... she doesn't deserve it', but went on to concede that, ' ... in general, they will be happy to see an Emirati in a (good) position'. This once again raises the issue of how Emiratis see themselves as being apart from the expatriate workforce, which is unsurprising, considering Emiratis in 2013, who made up just $0.5 \%$ of the private sector workforce.
Another negative reaction to managerial influence was highlighted by Fatma in the form of Wasta, a feature of Emirati society in which preferential treatment is given to family and friends with regard to position and promotion within a company. She cited this as an impediment on her otherwise flourishing career at the time by stating, 'I saw myself growing in that bank...but the problem was my manager was put there by Wasta. He knew nothing'. This in fact, was instrumental in Fatma leaving the company with the difficult decision to do so alluded to in her statement, '... there are external factors that force you sometimes to leave a place ... and I didn't want to leave that place'. Her action was in contrast to the usual passive acceptance of this societal phenomenon and indicated a self-belief in her ability of being able to find a job in another company where presumably she would be treated more fairly.

\section{Summary}

The interviews identified four themes: family-of-origin, ownfamily, workplace, and societal expectations. These themes represent the supports, resources, obstacles, and work conditions that contribute to the women's career development and satisfaction. Having completed the qualitative phase of this mixed method sequential explanatory study (Hanson et al., 2005), we now turn to the quantitative phase in Study 2.

\section{Study 2}

The aim of Study 2 was to quantitatively explore relations amongst the core variables identified in the SCCT, selfefficacy and outcome expectations, and their relation with work engagement.

\section{Participants}

There were $N=41$ participants whose ages ranged across the following categories: 20-25 years, 48.8\%; 26-30 years, 22\%; 31-34 years 9.8\%; and 35-40 years, $19.5 \%$. With respect to their education status, $4.9 \%$ held a master's degree, $68.3 \%$ a bachelor's degree, $12.2 \%$ a diploma, and $14.7 \%$ reported 'other' or unspecified, and approximately half of the participants (53.7\%) were enrolled in further studies. Relationship status were $63.4 \%$ single, $26.8 \%$ married, and 9.7\% divorced. The majority (80.3\%) had no children and $4.9 \%$ had one or two children, and a further 9.8\% had more than three children. Employment sectors included $36.5 \%$ in the private sector, $41.4 \%$ in the semi-private sector, and $21.9 \%$ in the public sector. Industries were $39 \%$ in banking and finance, $46.4 \%$ worked in 'other' unspecified industries, and $4.8 \%$ reported their industries as health, media and retail. The majority of participants (39\%) had worked in their current organisation for more than 4 years with $29.3 \%$ having worked for $2-3$ years, $17.1 \%$ for $1-2$ years and $14.6 \%$ for less than 1 year in their current organisation.

\section{Procedure}

Study 2 participants completed an online survey available on the Create Survey (2017) platform. Instructions and items were translated into Arabic by a professional translator. A college- 
level educator, fluent in Arabic, checked the final draft of the survey for accuracy. The survey's invitation to participate was distributed through a tertiary education college which acted as a third-party to culturally legitimise the invitation. The study was approved by the ethical review board of the University of Southern Queensland (Approval: H15REA252).

\section{Materials}

Occupational Self-Efficacy Scale (OSES; Rigotti, Schyns, \& Mohr, 2008). There were six items on this scale related to participant beliefs in their ability to manage various challenges in their job (e.g. I can remain calm when facing difficulties in my job because I can rely on my abilities). The participants rated each of the six items on a 5-point Likert scale ranging from 1 (Strongly Disagree) to 5 (Strongly Agree). The scale was scored as an average, all items were summed and then divided by the total number of items. Reliability coefficients for the OSES were between 0.85 and 0.90 over the five countries in which the scale was tested (Rigotti et al., 2008). The internal consistency of the items in the present sample was Cronbach's $\alpha=0.78$.

Sources of Self-Efficacy and Outcome Expectations Scale (SSEOE; Lent, Ireland, Penn, Morris, \& Sappington, 2017). Twelve items were used to assess personal mastery experiences, verbal persuasion, and vicarious learning as sources contributing to self-efficacy (e.g. I have been resourceful at gathering the information I need to make career-related decisions). The participants responded using a 5-point Likert scale of 1 (Strong Disagreement) to 5 (Strong Agreement). They were asked to reflect on their past experiences, including the influence of important others and role models, and how these may influence their future career decisions. Original Cronbach's alpha values suggested the sub-scales internal consistency reliability estimates of $\alpha=0.82$ (personal mastery), $\alpha=0.89$ (verbal persuasion) and vicarious learning $\alpha=0.83$ (Lent et al., 2017). The internal consistency of the items in the present sample was Cronbach's $\alpha=0.85$ for Personal Mastery, $\alpha=0.93$ for Verbal Persuasion, and $\alpha=0.89$ for Vicarious Learning. The full scale returned a Cronbach's $\alpha$ of 0.92 .

Vocational Outcome Expectations Scale - revised (VOES; McWhirter \& Metheny, 2009). Eleven items sought to elicit information from the participants about outcome expectations regarding career planning (e.g. I will have a career/occupation that is respected in our society). Because of an administrative error, item number 12 from the original scale was missing. A 4-point Likert scale from 1 (Strongly Disagree) to 4 (Strongly Agree) was used and was scored as an average, all items were summed and then divided by the total number of items. The original Cronbach's alpha score for the scale was 0.93 (McWhirter \& Metheny, 2009). The internal consistency of the items in the present sample was Cronbach's $\alpha=0.90$.

Utrecht Work Engagement Scale - 9 (UWES; Schaufeli, Bakker, \& Salanova, 2006). Nine items sought to explore participant feelings in relation to the workplace and overall work engagement (e.g. I am immersed in my work). They were asked to rate themselves on a 6-point Likert scale from 1 (Never) to 6 (Daily). The original Cronbach's alpha for the scale varied between 0.85 and 0.92 across 10 countries (Schaufeli et al., 2006). The internal consistency of the items in the present sample was Cronbach's $\alpha=0.96$ for the full-scale (i.e. nine items). For the subscales, the internal consistency coefficients were Cronbach's $\alpha=0.94$ for Vigour, $\alpha=0.89$ for Dedication, and $\alpha=0.87$ for Absorption.

\section{Results \\ Data screening}

Table 1 presents the descriptive statistics. There was no missing data from the 41 participants. The UWES' subscales had marginally high skew values higher than $|1|$ and the OSES and Absorption subscale had marginal kurtosis higher than |1|. Inspection of box plots revealed one case with relatively lower scores for occupational self-efficacy (OSE) and vocational outcome expectations (VOE); however, this case was retained for analyses.

\section{Relations amongst variables}

Table 2 presents the correlations amongst the measured variables. According to the SCCT, the sources of self-efficacymastery, verbal persuasion, vicarious learning - should correlate with self-efficacy. The significant correlation coefficients bear out this theoretical relation. Multiple regression analysis with the sources of self-efficacy entered simultaneously revealed a significant model $[R=0.57$, adjusted $R^{2}=0.28$, s.e. $=0.46, F(3,37)=6.15, p=0.00$, DurbinWatson $=2.05$ ] with only personal mastery as a significant predictor of self-efficacy [ $\beta=0.56, t=2.74, p=0.01]$.

Social cognitive career theory posits predictive relations between self-efficacy and outcome expectations, and the correlation between these two variables is evident in Table 2 . In addition to self-efficacy per s.e., we tested the relations between its sources and outcome expectations. Multiple regression with the sources entered simultaneously revealed a significant model $\left[R=0.81\right.$, adjusted $R^{2}=0.63$, s.e. $=0.26$, $F(3,37)=23.66, p=0.00$, Durbin-Watson $=2.20]$. Again, only personal mastery was the significant predictor $[\beta=0.62$, $t=4.45, p=0.00]$. We note, however, that verbal persuasion had a non-trivial albeit statistically non-significant contribution in the model which may reach significance in a larger data set $[\beta=0.23, t=1.99, p=0.05]$.

According to SCCT, self-efficacy should associate with work engagement. Although self-efficacy did not correlate with work engagement measured as a full scale, two of the sources of self-efficacy, personal mastery and vicarious learning did correlate. Multiple regression analysis with personal mastery and vicarious learning entered simultaneously revealed a significant model $\left[R=0.54\right.$, adjusted $R^{2}=0.26$, s.e. $=1.27$, $F(2,38)=7.85, p=0.001]$ with only personal mastery as a significant predictor of work engagement $[B=0.39, t=2.09$, $p=0.04,95 \% \mathrm{CI}=0.03,0.1 .80]$. 
TABLE 1: Descriptive statistics for the measures.

\begin{tabular}{|c|c|c|c|c|c|c|c|}
\hline Measure & $M$ & $M d n$ & s.d. & Skew & s.e. & Kurtosis & s.e. \\
\hline OSES & 4.22 & 4.33 & 0.55 & -0.83 & 0.369 & 1.38 & 0.724 \\
\hline UWES & 5.69 & 6.33 & 1.47 & -1.26 & 0.369 & 0.63 & 0.724 \\
\hline VOES & 3.55 & 3.63 & 0.43 & -0.81 & 0.369 & -0.20 & 0.724 \\
\hline SSEOE & 4.15 & 4.17 & 0.65 & -0.43 & 0.369 & -0.59 & 0.724 \\
\hline PM & 4.19 & 4.25 & 0.63 & -0.30 & 0.369 & -0.29 & 0.724 \\
\hline VP & 4.12 & 4.25 & 0.87 & -0.77 & 0.369 & -0.44 & 0.724 \\
\hline V & 5.49 & 6.00 & 1.56 & -1.11 & 0.369 & 0.54 & 0.724 \\
\hline D & 5.80 & 6.33 & 1.48 & -1.26 & 0.369 & 0.71 & 0.724 \\
\hline A & 5.80 & 6.33 & 1.55 & -1.40 & 0.369 & 1.54 & 0.724 \\
\hline
\end{tabular}

OSES, Occupational Self-Efficacy Scale; UWES, Utrecht Work Engagement Scale; VOES, Vocational Outcome Expectation Scale; SSEOE, Total Sources of Self Efficacy and Outcome Expectations; PM, SSEOE personal mastery, VP, SSEOE verbal persuasion; VL, SSEOE vicarious learning; V, UWES vigour; D, UWES dedication; A, UWES absorption; s.d., standard deviation; s.e., standard error.

TABLE 2: Correlations of the full scales and subscales of measures.

\begin{tabular}{|c|c|c|c|c|c|c|c|c|c|c|}
\hline Variable & 1 & 2 & 3 & 4 & 5 & 6 & 7 & 8 & 9 & 10 \\
\hline 1. OSES & - & & & & & & & & & \\
\hline 2. UWES & 0.24 & - & & & & & & & & \\
\hline 3. VOES & $0.61 * *$ & $0.42 * *$ & - & & & & & & & \\
\hline 4. SSEOE & $0.50 * *$ & $0.46^{* *}$ & $0.77^{* *}$ & - & & & & & & \\
\hline 5. PM & $0.54 * *$ & $0.52^{* *}$ & $0.78^{* *}$ & $0.85 * *$ & - & & & & & \\
\hline 6. VP & $0.43 * *$ & 0.14 & $0.59 * *$ & $0.82 * *$ & $0.55 * *$ & - & & & & \\
\hline 8. V & 0.27 & $0.97 * *$ & $0.41 * *$ & $0.38^{*}$ & $0.50 * *$ & 0.10 & $0.40 * *$ & - & & \\
\hline 9. D & 0.22 & $0.97 * *$ & $0.49 * *$ & $0.43 * *$ & $0.53 * *$ & 0.15 & $0.47 * *$ & $0.92 * *$ & - & \\
\hline 10. A & 0.21 & $0.95 * *$ & $0.33^{*}$ & $0.42 * *$ & $0.48 * *$ & 0.16 & $0.46 * *$ & $0.87 * *$ & $0.88 * *$ & - \\
\hline
\end{tabular}

OSES, Occupational Self-Efficacy Scale; UWES, Utrecht's Work Engagement Scale; VOES, Vocational Expectations and Outcomes Scale; SSEOE, Sources of Self Efficacy and Outcome Expectations. Subscales of SSEOE; PM, personal mastery; VP, verbal persuasion; VL, vicarious learning; Subscales of UWES; V, vigour; D, dedication; A, absorption.

Two tailed significance $* p<0.05, * * p<0.01$

\section{Discussion}

This research sought to explore the potential utility of the SCCT for research addressing entrepreneurial women in Dubai. There are two notable findings. Firstly, through the interviews in Study 1, we discerned proximal and distal contextual supports, resources, and obstacles, and work conditions which are consistent tenets of the SCCT, namely family-of-origin, own-family, workplace, and societal expectations. Secondly, the variables measured in Study 2 had correlations with one another at levels that were sufficiently consistent with the SCCT.

Social cognitive career theory contextualises vocational behaviour by situating its core cognitive constructs (i.e. selfefficacy, outcome expectations) amidst social-environmental constructs (e.g. contextual affordances), and by assuming that these factors influence one another. Whilst we cannot draw specific conclusions about the relations between the contextual factors in Study 1 (e.g. workplace) and the measured variables in Study 2 - because they are separate studies per s.e. - we speculate that the significant correlation between work engagement and outcome expectations is tentative evidence of the theoretical relations specified in the SCCT.

Germane to the assumptions of social cognitive paradigm and SCCT, the measured sources of personal mastery, verbal persuasion, and vicarious learning had significant correlations with self-efficacy and outcome expectations. Similarly, self-efficacy and outcome expectations were linked with one another. Vocational outcome expectations correlated with all measures of work engagement (i.e. vigour, dedication, absorption); however, self-efficacy did not which is inconsistent with SCCT's work satisfaction model (Lent \& Brown, 2006). Similarly, Badri et al. (2013) found no relation between self-efficacy and job satisfaction. We considered this ostensibly contradictory finding in light of the essential role of family-of-origin and own-family to the women in this study. Recent research highlights complex relations amongst nonwork family support, professional self-efficacy, and work engagement (Azim \& Al-Halawani, 2020) and self-efficacy for balancing work and family demands and work engagement (Chan et al., 2017; Wood, Oh, Park, \& Kim, 2020); however, Wood et al. concluded that the directionality of effects between life balance and work engagement is yet to be determined by research. We speculate that the women in this study had to similarly appraise their occupational self-efficacy in the context of family dynamics.

Contrary to the findings by Williams et al. (2013), participant careers did not appear to be restrained once they had accessed the private sector and proved their worth. In this study, family members showed unwavering support for their choices including change in career direction and other activities such as additional studies that may further enhance future careers. Specific mention was made in relation to support given by mothers. Less obvious is the specific influence of male family members on the women's careers. This finding is important because it suggests that there is a need to explore nuances of family 
influence on Emirati women from an SCCT perspective. For example, are the relationships between women and their parents qualitatively different in the case of mother and father? How do parental relationships influence selfefficacy and outcome expectations? In the present study, vicarious learning and verbal persuasion were evidently correlated with the women's self-efficacy. Are those sources of self-efficacy influenced by how women observe the work-related behaviour of their parents, and how they attend to their work-related discourse of their Emirati parents? Future research is needed to answer these questions and to further test the potential of the SCCT in this context.

If the tenets of the SCCT have merit in the socio-cultural and economic context of Dubai and the UAE, then attention should be given to designing and implementing strategies to support women's career exploration, decision-making, and transitions in the world-of-work. Initiatives such as the National Strategy for the Empowerment of Emirati Women (United Arab Emirates Government, 2021), the Dubai Women Establishment (Government of Dubai, 2021) and, the Dubai Business Women Council (Dubai Chamber of Commerce and Industry, 2021) are signs of structural reform. For career development researchers and practitioners, the challenge is to advocate for the field's theory, research, and practices to inform how those initiatives can be implemented to positively affect women's self-efficacy, outcome expectations, goals, and contextual factors that may enhance or limit their development.

\section{Limitations}

This research is inherently limited by its intent to explore SCCT's potential for use in the specific demographic group of interest (i.e. younger entrepreneurial Emirati women residing in Dubai). We did not advance specific hypotheses drawn from the SCCT and therefore the results should be interpreted as tentative evidence of the SCCT's utility. Notwithstanding statistically significant correlation and regression coefficients amongst the majority of variables, and acceptable Durbin-Watson coefficients in Study 2, the study's findings are limited by the small sample size and should not be taken as indication of the population of entrepreneurial women in Dubai. Accordingly, future research may aim to conceptually replicate the present study by using a larger sample to enable the use of confirmatory factor analysis to determine the measurement properties of the Arabic versions of the measures used in the study, and to use structural equation modelling to test SCCT hypotheses. Furthermore, given the findings of Study 1, we recommend including measures pertaining to contextual factors that involve family-of-origin, own-family, workplace, and societal expectations. There are significant challenges to recruiting participants of this demographic segment. Therefore, we recommend researchers to formulate a recruitment plan in conjunction with local personnel who possess expert knowledge of and respect of gender-related conventions.

\section{Conclusion}

In Dubai today, there are expectations that more women will become educated and venture out into the workforce; however, there remains ambiguity with respect to what are valorised roles for women in the workforce. The present study offers initial evidence of the SCCT's utility for conducting research into the careers of women in Dubai because of its conceptual scope to contextualise distal and proximal social-cognitive factors. Future research must determine how well the SCCT can be applied in the geographical region of Dubai and the $\mathrm{UAE}$, and other demographic segments.

\section{Data availability statement}

Because of the nature of this research, the participants of this study did not agree for their data to be shared publicly, so supporting data is not available.

\section{Acknowledgements Competing interests}

The authors have declared that no competing interest exist.

\section{Authors' contributions}

All authors contributed to the conceptualisation, design, and data analysis for the research. Pamela Hawkswell conducted the data collection. All authors contributed to the writing of the article.

\section{Ethical considerations}

Ethical clearance was obtained from the Human Research Ethics Committee of the University of Southern Queensland H15REA252.

\section{Funding information}

This research received no specific grant from any funding agency in the public, commercial or not-for-profit sectors.

\section{Data availability}

Data are not available for distribution as approved by the Human Research Ethics Committee of the University of Southern Queensland.

\section{Disclaimer}

The views and opinions expressed in this article are those of the authors and do not reflect the official policy or position of any affiliated agency of the authors.

\section{References}

Al-Waqfi Mohammed, A., \& Forstenlechner, I. (2012). Of private sector fear and prejudice: The case of young citizens in an oil-rich Arabian Gulf economy. Personnel Review, 41(5), 609-629. https://doi.org/10.1108/00483481211249139

Azim, M.T., \& Al-Halawani, F.M.J. (2020). Perceived non-work social support and employee engagement: The mediating role of self-efficacy. Middle East Journal of Management, 7(2), 166-184. https://doi.org/https://doi.org/10.1504/MEJM.2020.105946 
Badri, M.A., Mohaidat, J., Ferrandino, V., \& El Mourad, T. (2013). The social cognitive model of job satisfaction amongst teachers: Testing and validation. International Journal of Educational Research, 57, 12-24. https://doi.org/10.1016/j. ijer.2012.10.007

Barragan, S., Erogul, M.S., \& Essers, C. (2015). Alternate-feminine entrepreneurial identity: Explaining, persuading, convincing, and adapting. Academy of Management Proceedings, 2015(1), 18093. https://doi.org/10.5465/ ambpp.2015.18093abstract

Braun, V., \& Clarke, V. (2006). Using thematic analysis in psychology. Qualitative Research in Psychology, 3, 77-101. https://doi.org/10.1191/1478088706qp063oa

Braun, V., \& Clarke, V. (2013). Successful qualitative research: A practical guide for beginners. London: Sage.

Brown, S.D., \& Lent, R.W. (2019). Social cognitive career theory at 25: Progress in studying the domain satisfaction and career self-management models. Journa of Career Assessment, 27(4), 563-578. https://doi.org/10.1177/106 9072719852736

Cairns, D., \& Dickson, M. (2020). Exploring the relations of gender, science disposition and science achievement on STEM career aspirations for adolescents in public schools in the UAE. The Asia-Pacific Education Researcher, 30, 153-165. https:// doi.org/10.1007/s40299-020-00522-0

Chan, X.W., Kalliath, T., Brough, P., O’Driscoll, M., Siu, O.-L., \& Timms, C. (2017). Selfefficacy and work engagement: Test of a chain model. International Journal of Manpower, 38(6), 819-834. https://doi.org/10.1108/IJM-11-2015-0189

Dubai Chamber of Commerce and Industry. (2021). Dubai Business Women Council. Retrieved from https://www.dubaichamber.com/what-we-do/event-andnetworking/dubai-business-women-council

Erogul, M.S. (2011). Social capital impediments in the United Arab Emirates: A case of Emirati female entrepreneurs. Journal of Enterprising Culture, 19(3), 315-339. https://doi.org/10.1142/S0218495811000829

Erogul, M.S., Rod, M., \& Barragan, S. (2019). Contextualizing Arab female entrepreneurship in the United Arab Emirates. Culture and Organization, 25(5), 317-331. https://doi.org/10.1080/14759551.2016.1244824

Gallant, M., Majumdar, S., \& Varadarajan, D. (2010). Outlook of female students towards entrepreneurship. Education, Business and Society: Contemporary Middle Eastern Issues, 3(3), 218-230. https://doi.org/10.1108/175379810 11070127

Government of Dubai. (2021). Dubai women establishment. Retrieved from https:// dwe.gov.ae/en/about

Hanson, W.E., Creswell, J.W., Clark, V.L.P., Petska, K.S., \& Creswell, J.D. (2005). Mixed methods research designs in counseling psychology. Journal of Counseling Psychology, 52(2), 224-235. https://doi.org/10.1037/0022-0167.52.2.224
Howe-Walsh, L., Turnbull, S., Khan, S., \& Pereira, V. (2020). Exploring career choices of Emirati women in the technology sector. Journal of Organizational Effectiveness:
People and Performance, 7(1), 96-114. https://doi.org/10.1108/JOEPP-01-2020-0007

Lent, R.W., \& Brown, S.D. (2006). Integrating person and situation perspectives on work satisfaction: A social-cognitive view. Journal of Vocational Behavior, 69(2), 236-247. https://doi.org/10.1016/j.jvb.2006.02.006

Lent, R.W., \& Brown, S.D. (2019). Social cognitive career theory at 25: Empirical status of the interest, choice, and performance models. Journal of Vocational Behavior, 115, 103316. https://doi.org/10.1016/j.jvb.2019.06.004

Lent, R.W., Ireland, G.W., Penn, L.T., Morris, T.R., \& Sappington, R. (2017). Sources of self-efficacy and outcome expectations for career exploration and decisionmaking: A test of the social cognitive model of career self-management Journal of Vocational Behavior, 99, 107-117. https://doi.org/10.1016/j.jvb.2017.01.002

Marmenout, K., \& Lirio, P. (2014). Local female talent retention in the Gulf: Emirati women bending with the wind. The International Journal of Human Resource Management, 25(2), 144-166. https://doi.org/10.1080/09585192.2013.826916

McWhirter, E.H., \& Metheny, J. (2009). Vocational Outcome Expectations-Revised. A revised measure of expectations associated with high school career planning. Unpublished measure.

Rigotti, T., Schyns, B., \& Mohr, G. (2008). A short version of the Occupational SelfEfficacy Scale: Structural and construct validity across five countries. Journal of Career Assessment, 16(2), 238-255. https://doi.org/10.1177/1069072707305763

Schaufeli, W.B., Bakker, A.B., \& Salanova, M. (2006). The measurement of work engagement with a short questionnaire: A cross-national study. Educational and Psychological Measurement, 66(4), 701-716. https://doi.org/10.1177/001316 4405282471

Sheu, H.-B., \& Bordon, J.J. (2017). SCCT research in the international context: Empirical evidence, future directions, and practical implications. Journal of Career Assessment, 25(1), 58-74. https://doi.org/10.1177/1069072716657826

United Arab Emirates Government. (2021). National strategy for empowerment of Emirati women. Retrieved from https://u.ae/en/about-the-uae/strategiesinitiatives-and-awards/federal-governments-strategies-and-plans/nationalstrategy-for-empowerment-of-emirati-women

Williams, A., Wallis, J., \& Williams, P. (2013). Emirati women and public sector employment: The implicit patriarchal bargain. International Journal of Public Administration, 36(2), 137-149. https://doi.org/10.1080/01900692.2012.721 438

Wood, J., Oh, J., Park, J., \& Kim, W. (2020). The relationship between work engagement and work-life balance in organizations: A review of the empirical research. Human Resource Development Review, 19(3), 240-262. https://doi. org/10.1177/1534484320917560 